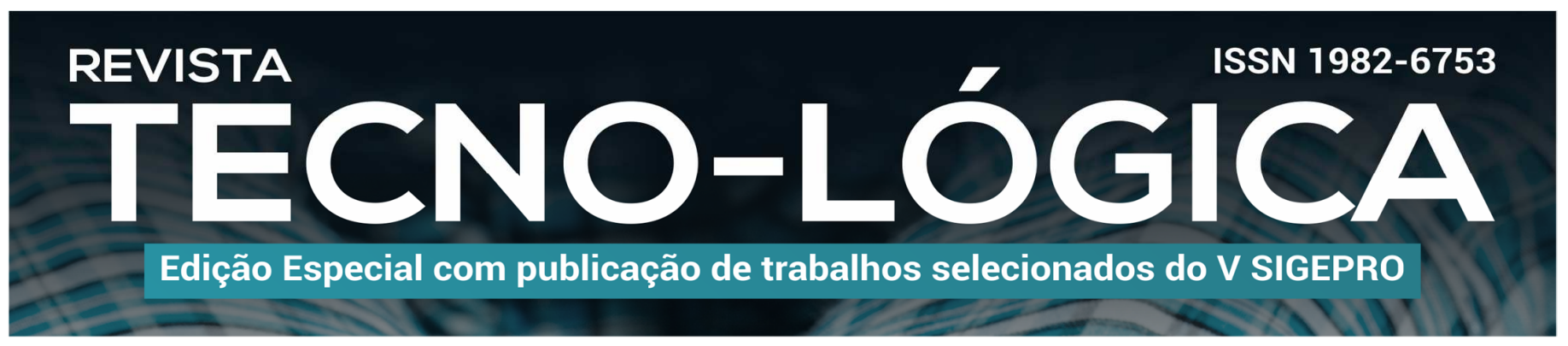

\title{
AVANÇO DE DESEMPENHO PRODUTIVO COM A IMPLEMENTAÇÃO DO TRABALHO PADRONIZADO EM UMA CÉLULA DE MANUFATURA
}

Rodrigo Bergmann Anselmo ${ }^{1}$, Macáliston Gonçalves Da Silva ${ }^{2}$, Rafael Maciel Da Silva ${ }^{1}$, Victor Urach Bianchini ${ }^{1}$

1. Departamento de Engenharia de Produção, Universidade Luterana do Brasil - ULBRA, CEP 92425-900, Canoas, Brasil.

*E-mail: macaliston@ulbra.edu.br

Recebido em: 17/09/2020

Aceito em: $11 / 11 / 2020$

DOI: 10.17058/tecnolog.v2i0.15623

\section{RESUMO}

O presente artigo detalha e avalia a implementação do trabalho padronizado em uma célula de manufatura. O objetivo do estudo é aumentar o desempenho produtivo de uma empresa brasileira do setor de implementos agrícolas. Para atender esta demanda interna de melhoria, uma pesquisa-ação foi conduzida para desenvolver um plano de atuação com base no pensamento enxuto, explorar os dados originais do ambiente estudado, propor soluções e analisar os impactos com a aplicação do trabalho padronizado no contexto investigado. Os resultados alcançados foram a redução de 53\% nas atividades que não agregam valor, a redução de $30 \%$ na movimentação do operador dentro da célula, a redução de $15 \%$ de retrabalhos, a redução de 5\% em paradas da célula por falta de matéria-prima, a redução de 7\% no tempo de ciclo da célula e o aumento de 15 pontos percentuais na disponibilidade da célula pesquisada. De forma geral, a implementação do trabalho padronizado na empresa objeto de estudo permitiu efetivo controle do conteúdo das atividades, das sequências e dos tempos pré-determinados para a realização das tarefas. Assim como, atividades geradoras de desperdício foram identificadas e minimizadas, o fluxo do processo tornou-se visível, o treinamento da operação foi simplificado e a gestão visual no posto de trabalho foi adotada.

Palavras-chave: Produção enxuta. Trabalho padronizado. Pesquisa-ação.

\section{Introdução}

A melhoria contínua de processos e produtos eleva o nível de competitividade das organizações [1-2]. Nesta esteira, o pensamento enxuto (lean thinking) é uma alternativa utilizada para

TECNO-LÓGICA, Santa Cruz do Sul, v. 24, n. nesp, p. 289-299, jul./dez. 2020 modelar a gestão das empresas nos mais diversos seguimentos durante a jornada [3-5].

No modelo de gestão lean o desempenho diferenciado em lucratividade, eficiência, qualidade e atendimento ao cliente [6] é alcançado com ações centradas na eliminação de desperdícios

A matéria publicada nesse periódico é licenciada sob forma de uma Licença Creative Commons - Atribuição 4.0 Internacional http://creativecommons.org/licenses/by/4.0/ 


\section{REVISTA}

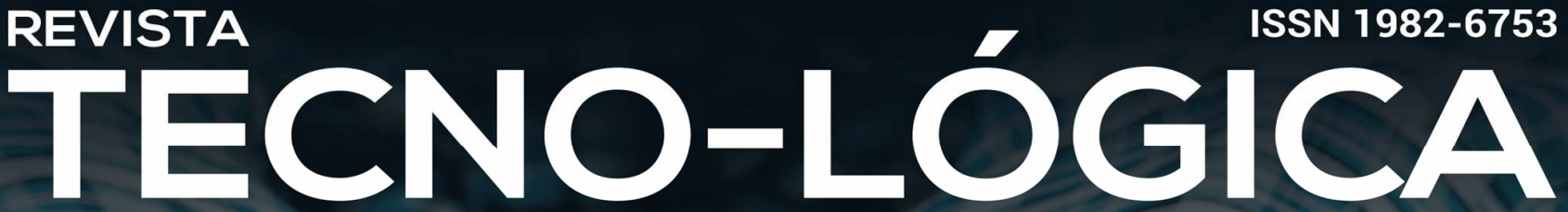

Edição Especial com publicação de trabalhos selecionados do V SIGEPRO

(muda) [7]. Como apoio, um conjunto de práticas lean vem sendo adotado para promoção da excelência operacional, tais como: kaizen [8]; setup rápido [9]; kanban [10]; poka-yoke [11]; nivelamento de produção [12]; trabalho padronizado [13].

Apesar de diversos estudos apontando para alternativas gerenciais direcionadas a operações de excelência, como os métodos e técnicas lean, muitos negócios no Brasil ainda possuem processos com baixos desempenhos, ainda agravados pela situação de enfrentamento à pandemia de Coronavírus (COVID19). Desta forma, estruturar caminhos para as empresas carentes de rotinas pode potencializar ganhos de competitividade na indústria nacional e consolidar possíveis aprendizagens gerais com projetos de melhoria de desempenho. Por meio de pesquisaação, o objetivo geral do presente estudo é implementar o trabalho padronizado em uma célula de manufatura para aumentar o desempenho produtivo em uma empresa brasileira do setor de implementos agrícolas. Além de atender uma demanda interna de melhoria na área pesquisada, tal objetivo é desdobrado em: (i) desenvolver um plano de atuação com base no pensamento enxuto; (ii) levantar dados originais do ambiente estudado; (iii) propor soluções e analisar os resultados alcançados com a aplicação do trabalho padronizado no contexto investigado.

\section{Referencial Teórico}

O processo de implementação do trabalho padronizado permite a eliminação de atividades que não agregam valor [13]. Destacado como uma das práticas mais frequentes na gestão da produção e como apoio à melhoria contínua [14], o trabalho padronizado é útil para redução da variabilidade nos sistemas produtivos [15]. Esta abordagem é utilizada visando a melhoria em processos de remanufatura [16], em linha de montagem manual na indústria eletrônica [17], em linha de montagem da indústria automotiva [18] e de tratores [19], entre outros.

Na implantação do trabalho padronizado, há três elementos condicionantes para um processo bem-sucedido (Figura 1) [13]: (i) takt time; (ii) sequência do trabalho; (iii) estoque padrão.

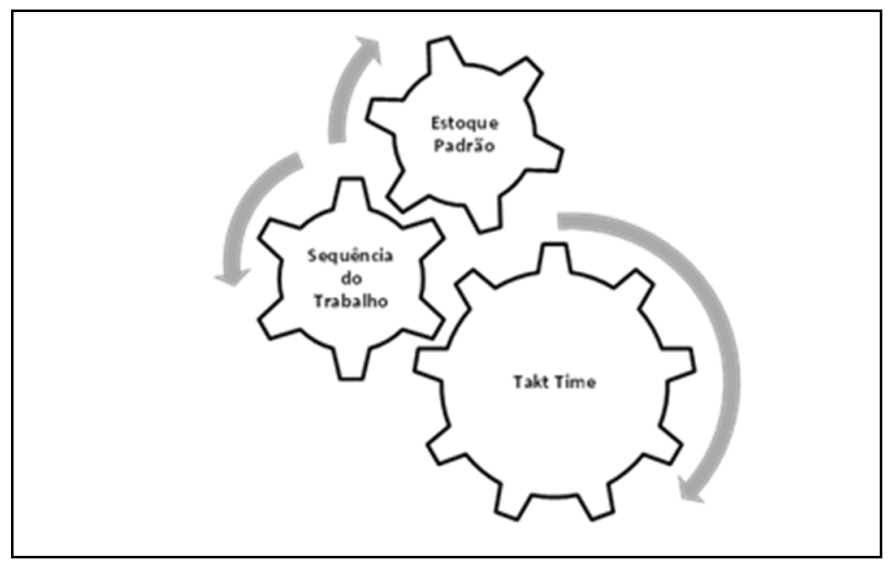

Figura 1 - Elementos fundamentais do trabalho padronizado [19].

O takt time é o ritmo padrão necessário para atendimento do cliente. Representa a taxa de finalização dos produtos em um processo para responder à demanda do cliente. A sequência do trabalho corresponde à ordenação das operações vinculadas aos limites do takt time. É o conjunto ordenado de atividades e tempos de execução dentro do takt time especificado. Já o estoque padrão é a quantidade necessário de unidades em processo, suficiente para o funcionamento contínuo da produção. É o mínimo de estoque possível, incluindo unidades em máquinas, para manter o processamento ativo sem espera entre etapas produtivas ou, ainda, outro tipo de desperdício [13, 19].

Considerado a base para um ciclo eficiente de melhoria contínua e treinamentos profissionais [20], o trabalho padronizado 


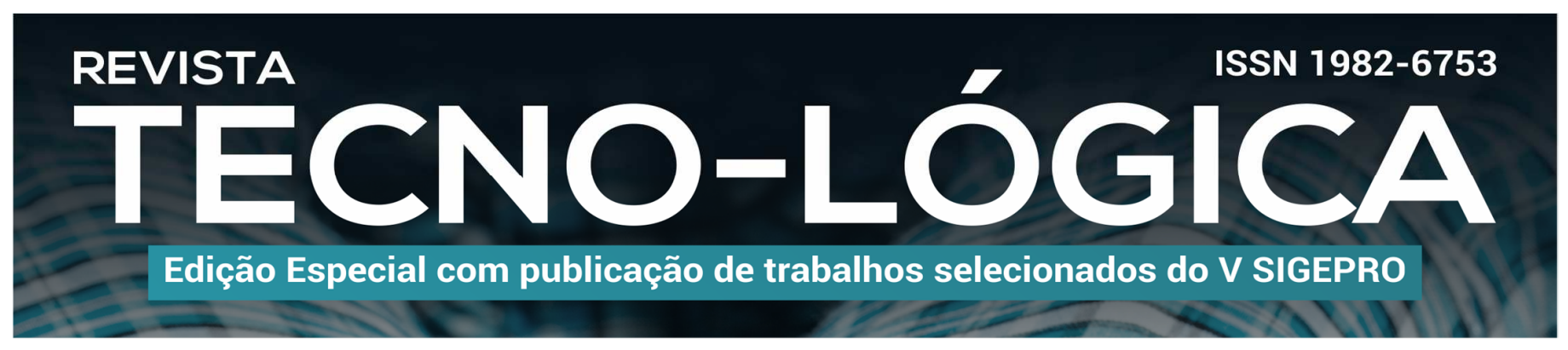

detalha os procedimentos operacionais direcionados à uniformidade de desempenho na organização [14]. O desenvolvimento da operação padrão conduz a transparência no fluxo de trabalho e a eliminação dos 3Ms (muda, muri, mura) [13].

A partir da execução do trabalho padronizado é possível alcançar benefícios como a melhoria da qualidade, a formação de parâmetros para melhoria, a redução da variabilidade [21], o aumento da produtividade, o aumento da segurança contra acidentes, a documentação de processo atualizada [13], a satisfação dos operadores, a simplificação de treinamentos e a redução de estoque em processo [19].

\section{Método}

A abordagem de pesquisa utilizada é qualitativa e de natureza aplicada, sendo o objeto de estudo uma célula de manufatura de uma empresa de implementos agrícola. Como adotado por De Freitas e Da Silva [19] e Mor et al. [13], o método de investigação é a pesquisa-ação.

Justifica-se a abordagem pela função pesquisadorparticipante interferindo no objeto de estudo, em conjunto com a equipe de profissionais locais, para a resolução do caso prático, além da contribuição para a base teórica [22]. As etapas de desenvolvimento da pesquisa-ação estão na Figura 2.

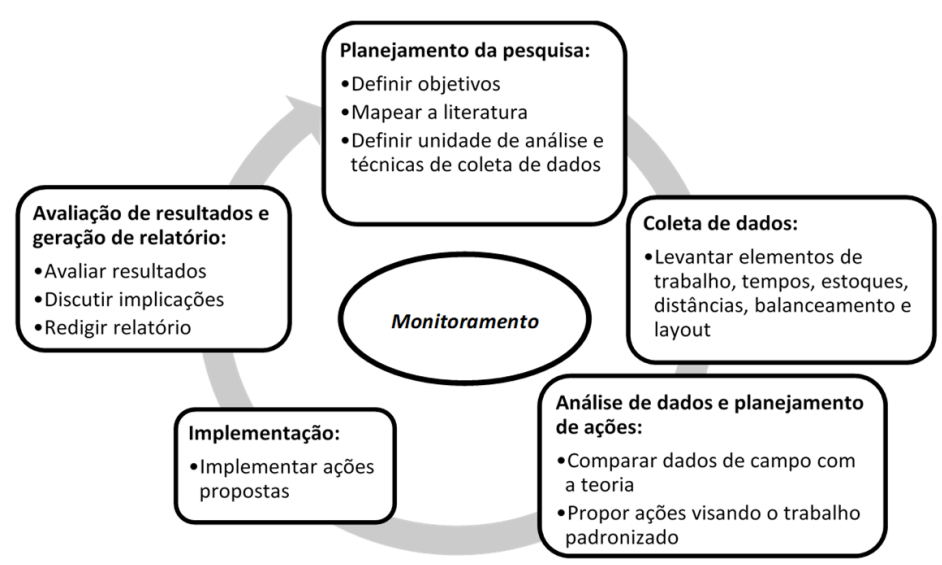

Figura 2 - Etapas adaptadas para proposta de pesquisa-ação [19, 22].

\section{Resultados da Pesquisa}

\subsection{Planejamento Inicial}

O trabalho foi direcionado para uma célula de manufatura em uma metalúrgica fornecedora de componentes beneficiados para montadoras de máquinas agrícolas. Atualmente, a empresa não atinge a produtividade ideal, conforme disponibilidade existente, sendo perceptível a falta de procedimentos operacionais na montagem do produto, dificuldades para o sequenciamento das atividades e excesso de estoque de componentes para abastecimento dos postos de trabalho. Os especialistas, profissionais envolvidos no projeto de implementação do trabalho padronizado foram: um líder de produção, um programador técnico, dois operadores e um supervisor de produção.

Um passo da pesquisa foi o aprofundamento na literatura específica para maior domínio sobre a aplicação do trabalho padronizado. Parte desta atividade está no referencial teórico deste artigo. Todos os participantes estavam alinhados com a filosofia lean após treinamentos executados durante o estudo, apoiados pela 


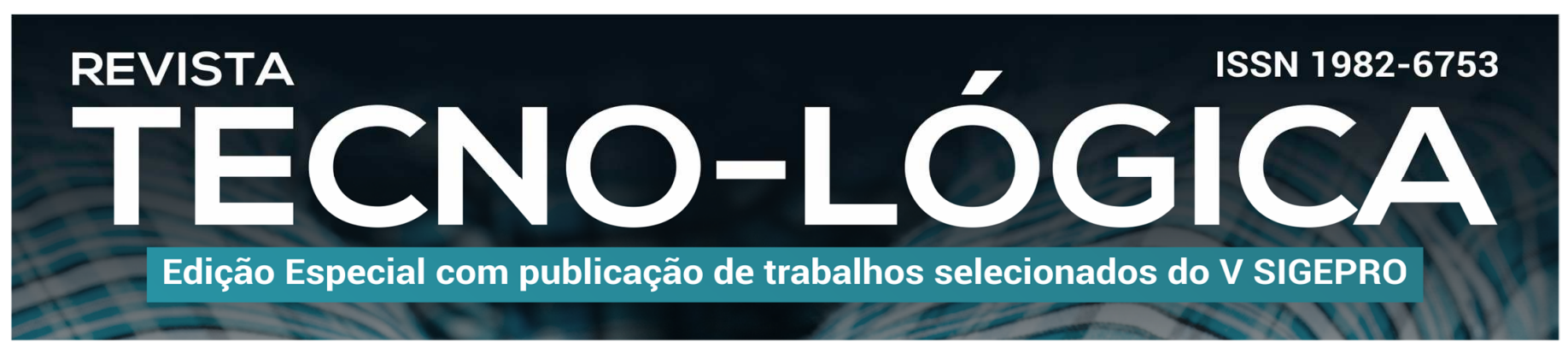

revisão da literatura. O projeto abordou apenas uma das 10 células semelhantes e ativas na empresa. Esta célula é dedicada à fabricação de um tipo específico e representativo de componente soldado para máquinas agrícolas. As técnicas de coleta de dados planejadas para o estudo foram: filmagens do ciclo de trabalho; observação direta na célula de manufatura e levantamento de dados do sistema de gestão da empresa.

\subsection{Coleta de Dados}

A partir da situação atual de processo, foram levantados os fatores de trabalhos, sequência de trabalho, tempos de ciclo e deslocamentos. Durante o processo de filmagem foi possível identificar as tarefas realizadas no abastecimento e na liberação da peça produzida em paralelo com o processo de soldagem do robô, que estava com tempo sobreposto entre máquina e operador. Posteriormente, foi executada a filmagem e a cronometragem do trabalho na célula em estudo, para obtenção dos tempos de realização das atividades em cada processo de liberação de um produto pronto, que permitiu o desmembramento do trabalho total realizado em elementos de trabalho, além da definição dos respectivos tempos de ciclo. $\mathrm{O}$ detalhamento dos fatores iniciais é mostrado nas Tabelas 1 e 2 .

Tabela 1 - Fatores de trabalho, sequência de trabalho e tempos de ciclo.

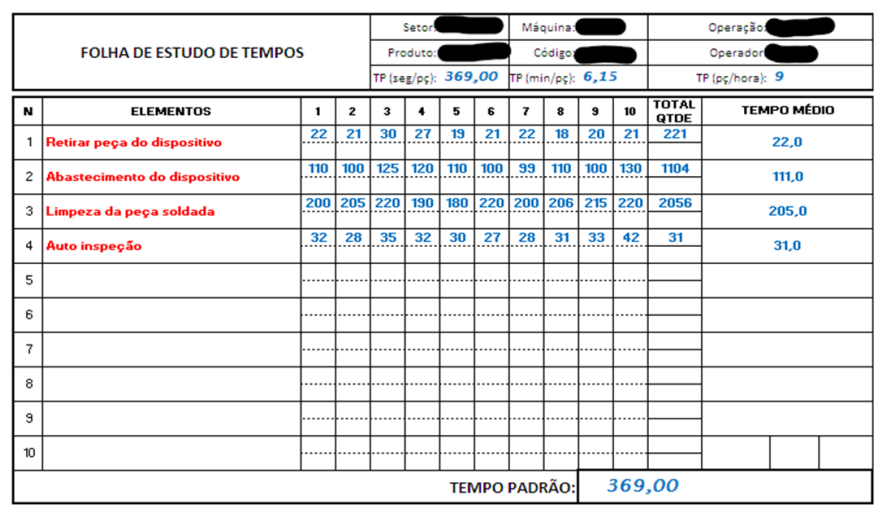

Tabela 2 - Tempo de soldagem robotizada em processo paralelo.

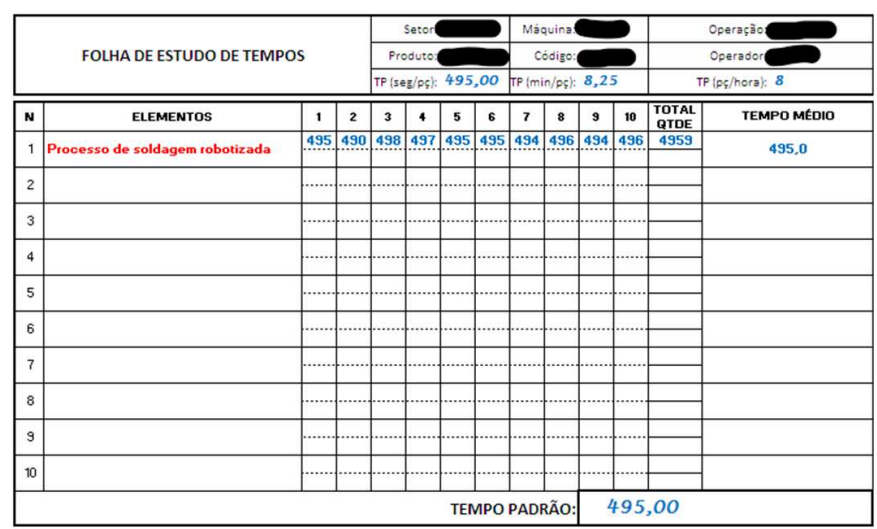

Informações relativas ao deslocamento do operador dentro da célula de trabalho durante o período de ciclo de processo foram apoiadas por diagrama de espaguete [23] (Figura 3). Conforme arranjo físico original, o deslocamento do operador registrado na célula em um dia de trabalho foi de 8000 metros, nos dois turnos de trabalho.
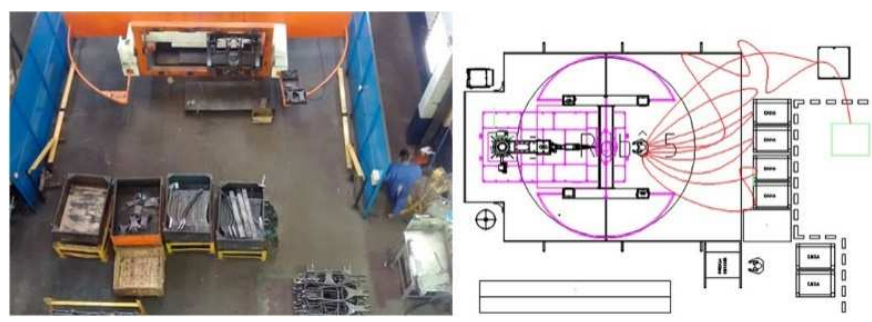

Figura 3 - Layout e diagrama de deslocamento na célula de trabalho.

A partir disso, foi possível levantar o estado inicial do balanceamento da célula com a construção do gráfico Yamazumi [24] (Figura 4). Tais evidências proporcionaram condições de análise da utilização dos recursos.

A matéria publicada nesse periódico é licenciada sob forma de uma Licença Creative Commons - Atribuição 4.0 Internacional http://creativecommons.org/licenses/by/4.0/ 


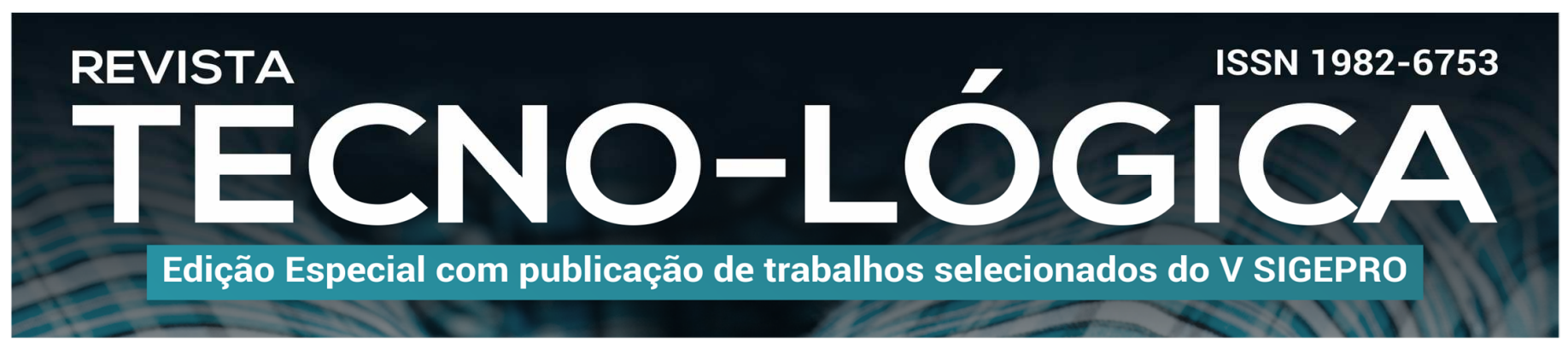

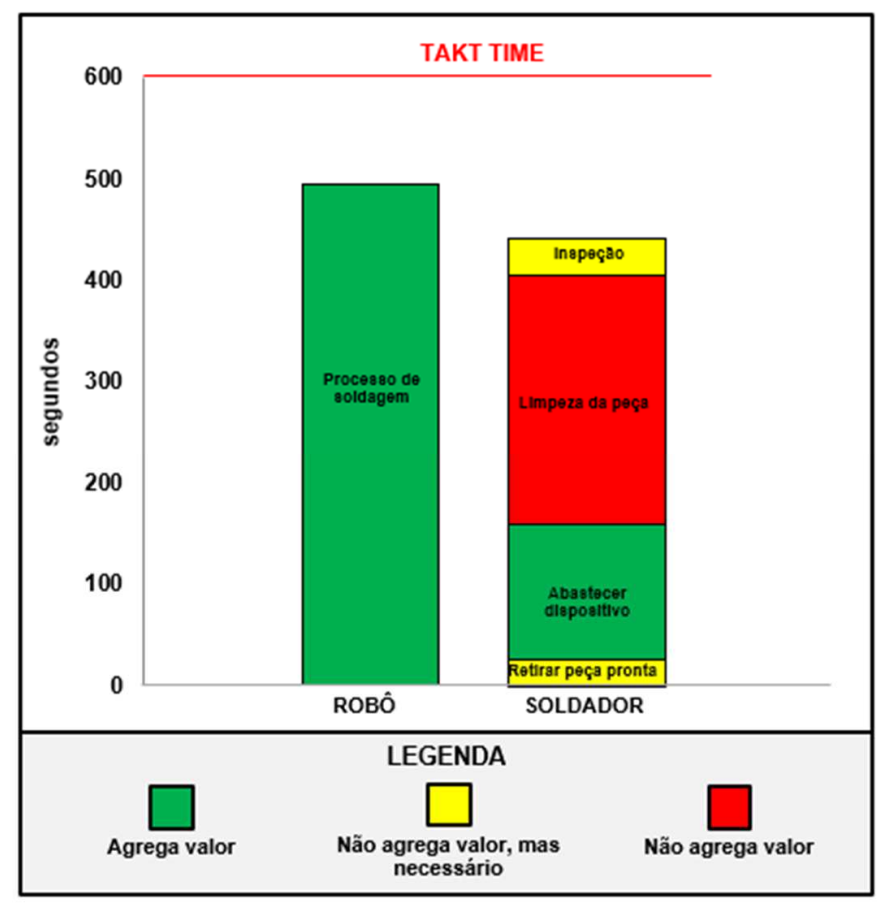

Figura 4 - Gráfico Yamazumi inicial da célula de manufatura.

A Figura 4 ilustra as tarefas entre o robô e o operador (soldador) em comparação com o takt time definido para a célula de manufatura, expondo o que realmente agrega valor no processo dessa célula. A Tabela 3 compara os tempos de ciclo da máquina e do operador com o takt time. Apesar de estarem abaixo do takt time, a operação depende em paralelo do operador com excesso de tempo em atividade que não agrega valor, a qual está ocasionando paradas não programadas no robô, logo, quedas nos volumes produzidos da célula.

Tabela 3 - Estado atual dos tempos de ciclo e takt time entre máquina e operador.

\begin{tabular}{ccc}
\hline Recurso & Tempo de ciclo (s) & Takt $(\mathbf{s})$ \\
\hline Robô & 495 & 600 \\
Operador & 369 & \\
\hline
\end{tabular}

A Figura 5 mostra os resultados das semanas 35 e 36 que possuem soma de 83 horas de programação, representadas por hora-máquina entre dois turnos de trabalho. A produção final de cada semana resultou em 54 horas apontadas na semana 35 e 60 horas na semana 36. A relação entre tempo apontado e tempo programado indica a disponibilidade da célula, no caso, $65 \%$ na semana 35 e $72 \%$ na semana 36 . O objetivo de disponibilidade da célula na empresa é alcançar índice igual ou superior a $85 \%$.

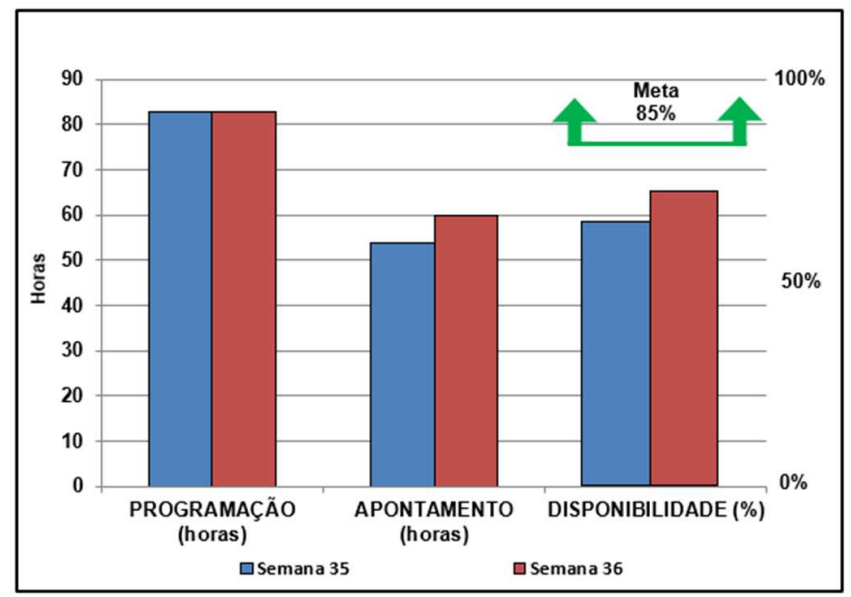

Figura 5 - Indicadores iniciais da célula de manufatura.

\subsection{Análise de Dados e Planejamento das Ações}

$\mathrm{O}$ pensamento lean aplicado nesta etapa direcionou a análise e as sugestões de mudanças. Parte-se da identificação e eliminação de desperdícios encontrados na célula de manufatura, levando as definições de padrões de trabalho. $\mathrm{O}$ foco foi atender os princípios do trabalho padronizado, orientado pelos seguintes objetivos:

- Atender o takt time com proporcionalidade ao tempo de ciclo em $80 \%$;

- Manter o fluxo contínuo dentro da célula de manufatura; 


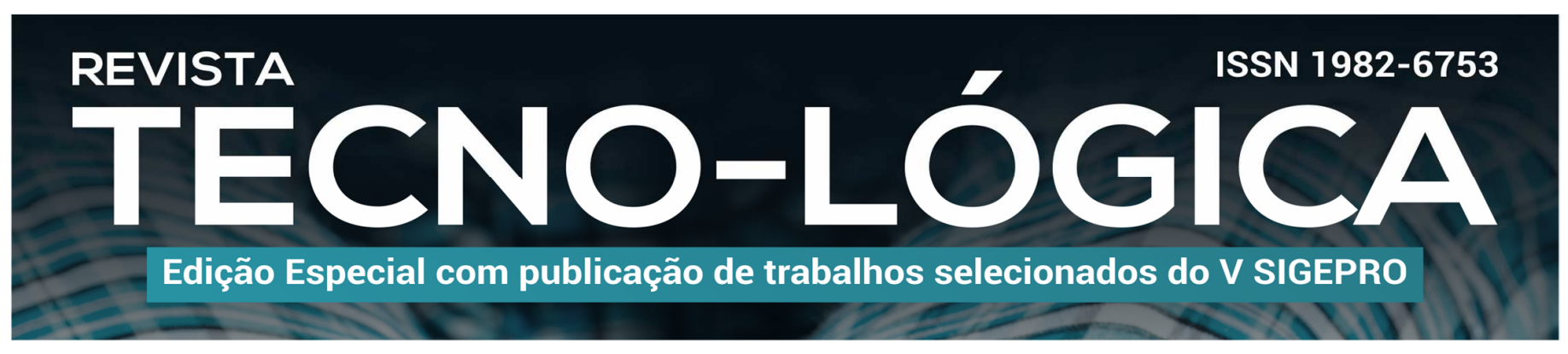

- Balancear as atividades do operador;

- Produzir conforme plano de trabalho.

Com o auxílio das planilhas de tempo dos fatores de trabalho (Tabelas 1 e 2), foram avaliados e ajustados os movimentos dentro da célula no melhor fator possível. Perdas em processo foram identificadas, eliminadas ou reduzidas. Com os resultados obtidos depois dos padrões estabelecidos, foi elaborada a folha de processo com parâmetros relativos a critérios de aceitação, plano de controle com respectivos sequenciamentos, parâmetros de soldagem, resumo de simbologias de soldagem e dimensionais, conforme requisitos em desenho. Nessa folha constam ainda desenhos $3 \mathrm{D}$ da peça e fotos que exemplificam o trabalho de controle para liberação do componente da célula de manufatura.

Levando em consideração os dados sintetizados nas Figuras 3 e 4 e na Tabela 3, é possível diminuir os tempos que não agregam valor na operação manual, através de treinamento nos novos padrões estabelecidos. O resultado da análise com as propostas de mudanças é visto no gráfico Yamazumi da Figura 6. A Tabela 4 mostra a comparação entre os tempos de ciclo projetados para os recursos e o takt time da célula de manufatura, conforme a demanda do cliente.

TECNO-LÓGICA, Santa Cruz do Sul, v. 24, n. nesp, p. 289-299, jul./dez. 2020

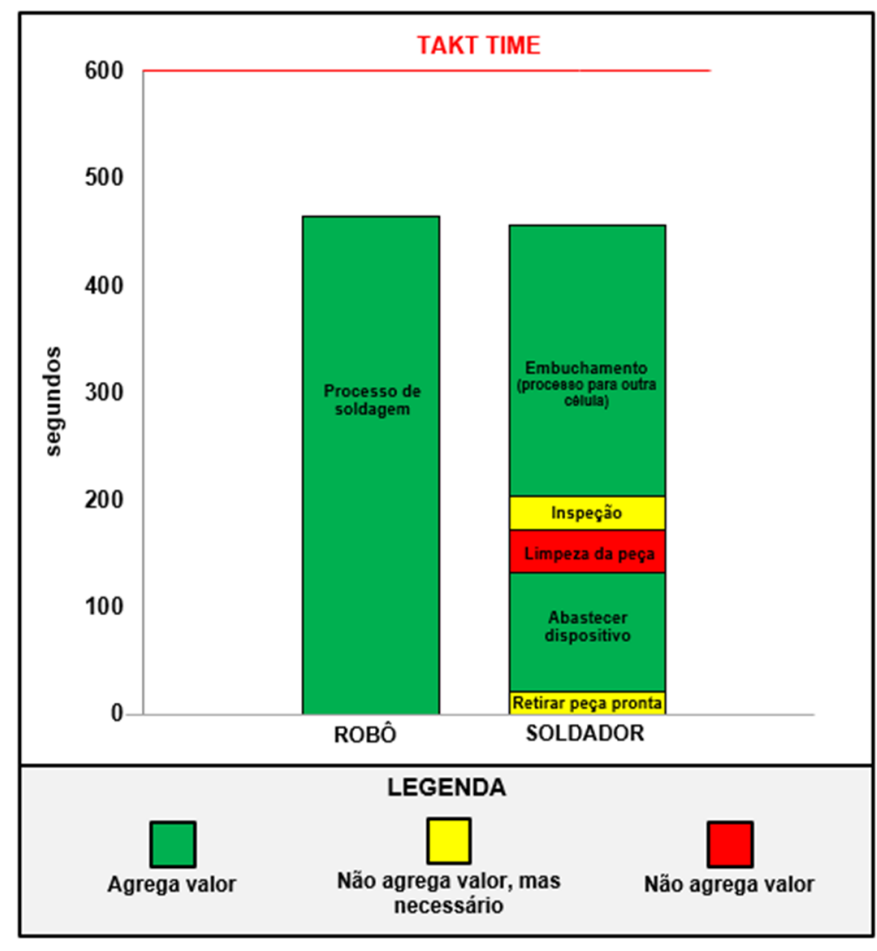

Figura 6 - Gráfico Yamazumi projetado para a célula de manufatura.

Tabela 4 - Comparação dos tempos de ciclo projetados em relação ao takt time.

\begin{tabular}{ccc}
\hline Recurso & Tempo de ciclo (s) & Takt (s) \\
\hline Robô & 464 & 600 \\
Operador & 457 & \\
\hline
\end{tabular}

Entre as ações, após análise para implementação do trabalho padronizado, foi definido a colocação de kanban para eliminação das paradas de máquina por falta de componentes. A partir do aproveitamento de espaço de uma das antigas caixas de transporte, juntamente com o balanceamento do fluxo da linha, foi feita uma aproximação física e diminuição na quantidade de embalagens para armazenagem de componentes. Desta forma, diminuindo a caminhada do operador em 2400 metros em um turno de trabalho. A identificação das embalagens com o código da peça e seu desenho 3D tende a melhorar a operação, evitando 


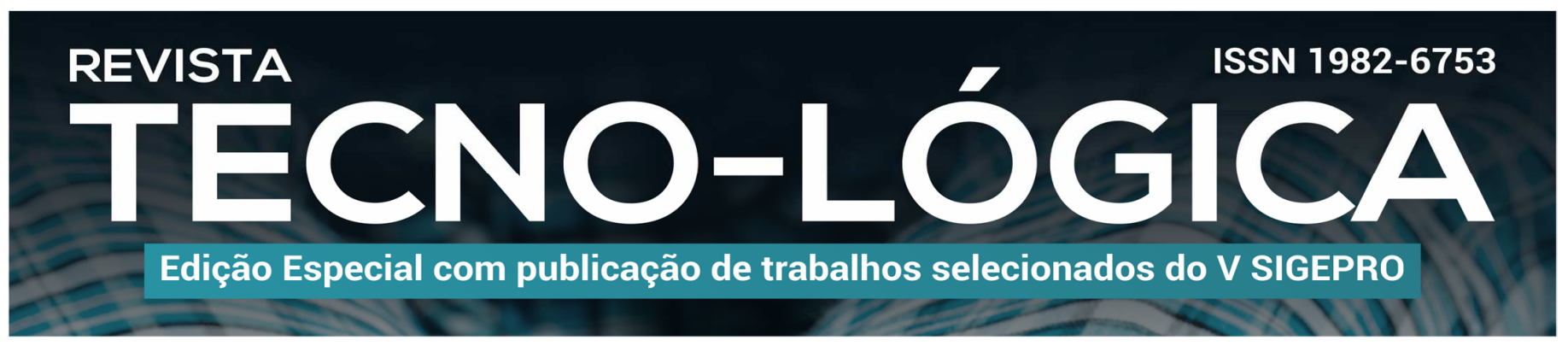

trocas de posição e quebras no sequenciamento de abastecimento da máquina. A Figura 7 mostra as modificações físicas na célula de manufatura após análises, já a Figura 8 ilustra os indicadores semanais projetados.
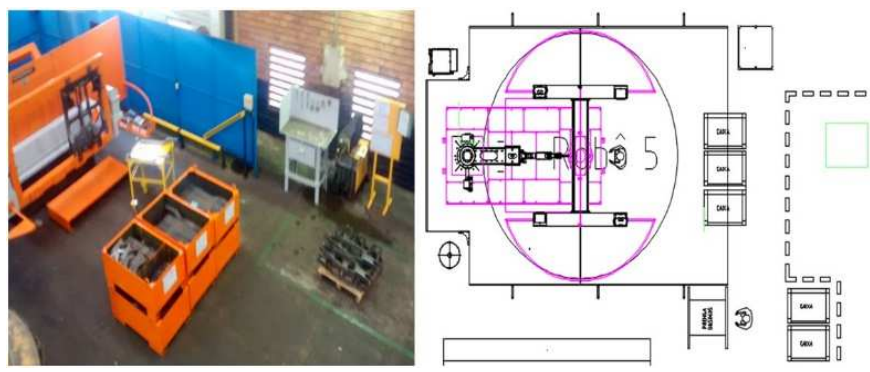

Figura 7 - Layout ajustado para atender o trabalho padronizado.

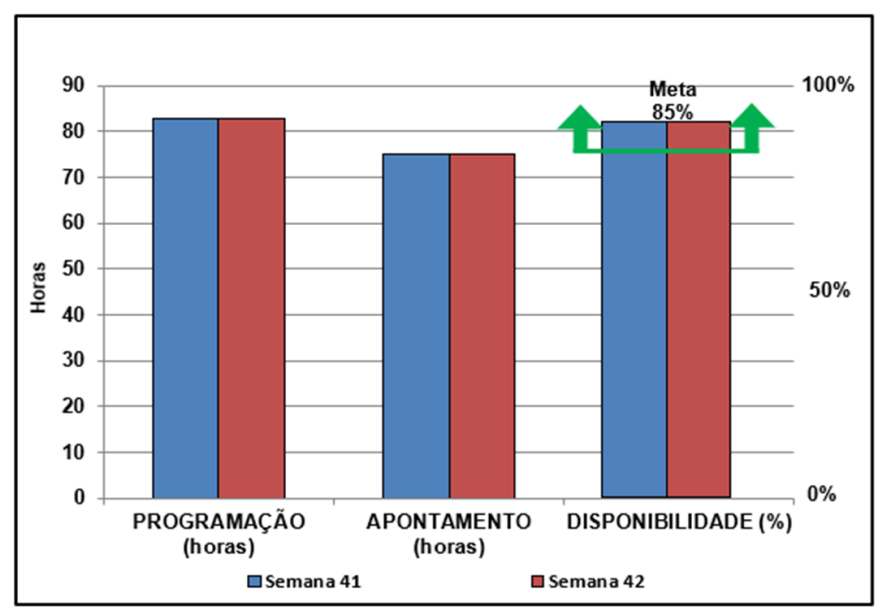

Figura 8 - Indicadores projetados para a célula de manufatura.

\subsection{Implementação}

Para acompanhamento e participação de todos os envolvidos na implementação do trabalho padronizado foram realizadas reuniões semanais, com o intuito de verificar possíveis distorções e investir imediatamente em treinamento e ações corretivas, se necessário. Não foram evidenciadas dificuldades junto à mão de obra. Inclusive, um ponto positivo foi o número de operadores aptos ao posto de trabalho, o que facilitou o relacionamento entre técnicos e operadores, sem receios de críticas construtivas. Este fato colaborou no resultado do trabalho, pois através da confiança, a comunicação dentro do grupo ficou mais eficaz. Com a aproximação do alcance das metas estabelecidas para a célula de manufatura e a prática acontecendo conforme planejado, o ambiente de trabalho ficou mais harmonioso. Sugestões para ajustes aconteceram em um processo natural de uma equipe dedicada e motivada. As melhorias na sequência de trabalho seguiram as argumentações de De Freitas e Da Silva [19], não superando a proporcionalidade de $80 \%$ entre o tempo de ciclo e o takt time. A Tabela 5 mostra os resultados obtidos nesta fase, em que o tempo de ciclo inicial da célula estava em $82 \%$ do takt time e, após ajustes, foi possível diminuir para $77 \%$ esta relação.

Tabela 5 - Comparação dos tempos de ciclo projetados em relação ao takt time.

\begin{tabular}{cccc}
\hline Recurso & Tempo de ciclo [TC] (s) & Takt [TT] (s) & TC / TT (\%) \\
\hline Robô & 464 & 600 & 77,3 \\
Operador & 457 & & 76,1
\end{tabular}

Mesmo não atingindo a meta em uma das semanas, foi possível verificar a possibilidade de evolução com a implementação do trabalho padronizado na célula de manufatura. A Figura 9 ilustra a situação. 


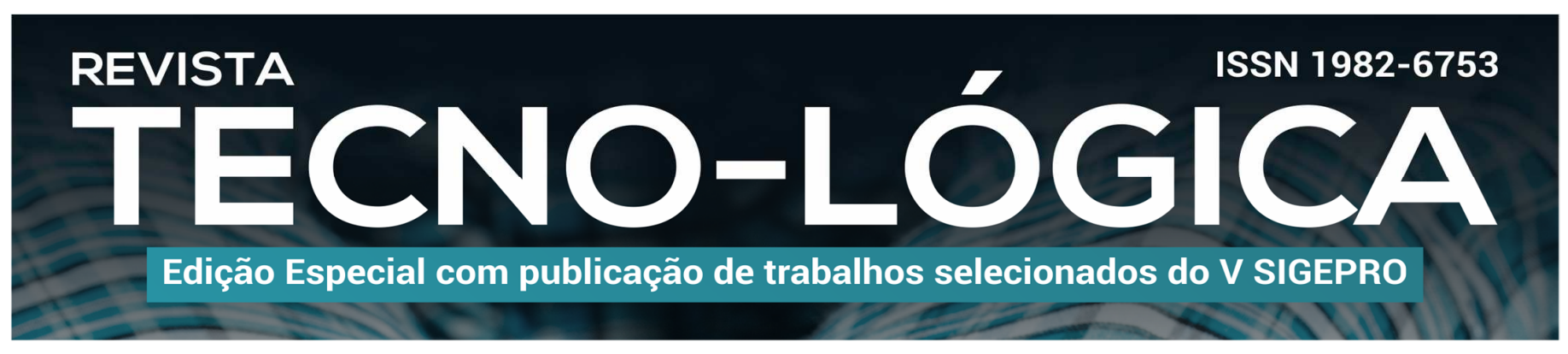

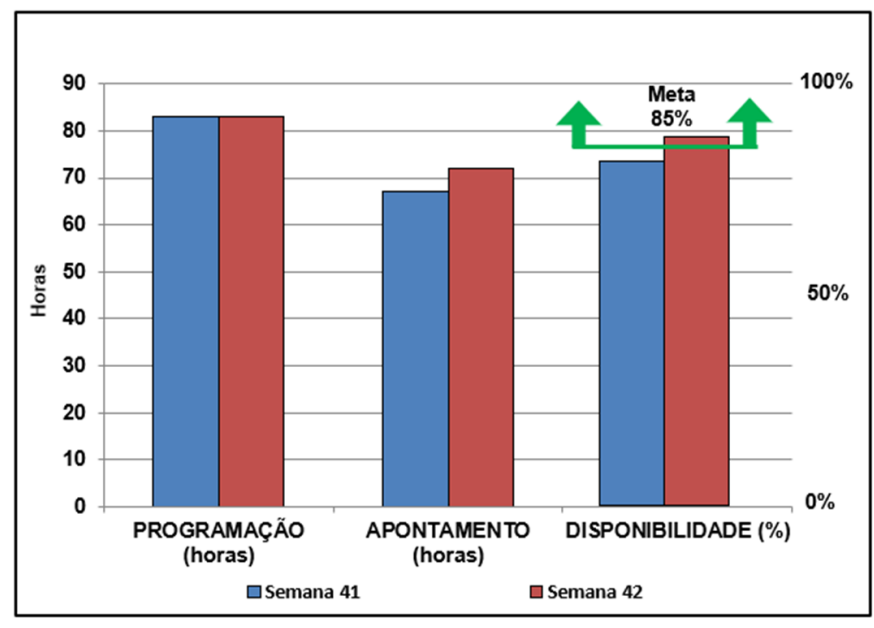

Figura 9 - Indicadores após implementação do trabalho padronizado.

Uma ferramenta importante utilizada na identificação de perdas na célula foi o controle de produção, o que auxiliou na identificação dos pontos críticos e de problemas. Esse instrumento (Figura 10) também abrange a meta diária para a produção na célula de manufatura, ampliando a condição de comunicação e acompanhamento da operação.

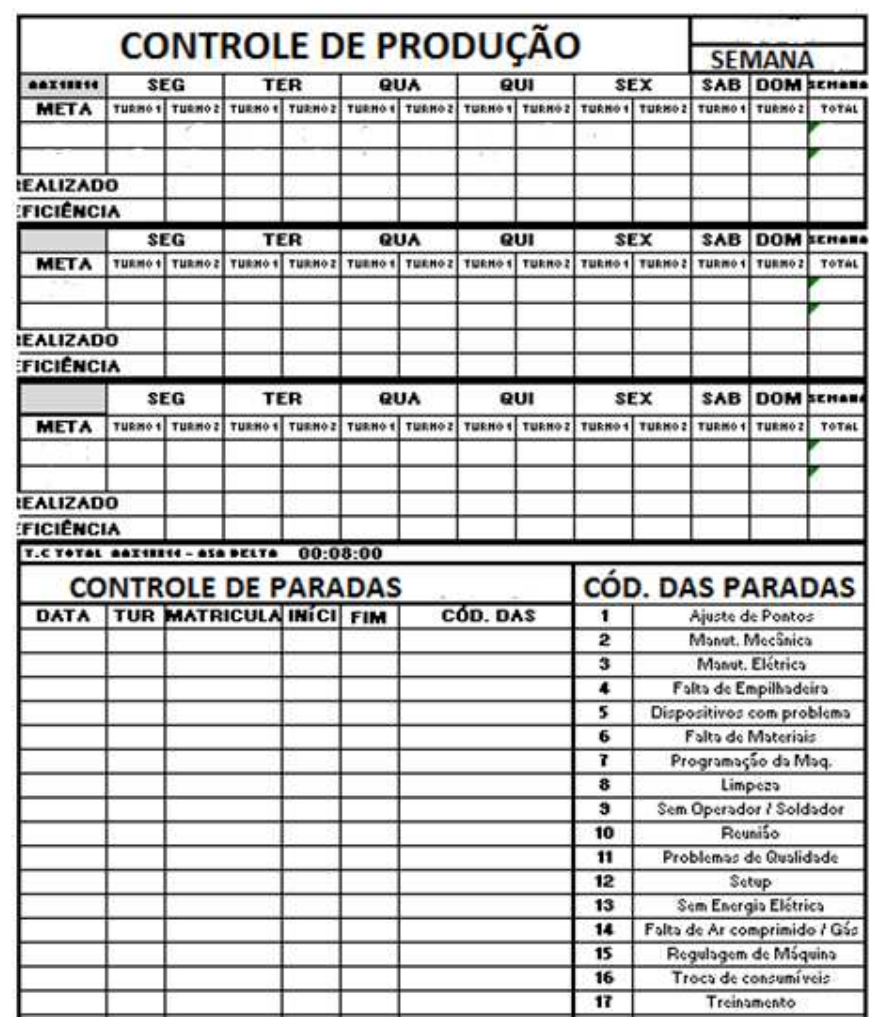

Figura 10 - Controle de parada da célula.

Segue a relação de resultados observados na célula de manufatura:

- Redução de 53\% nas atividades que não agregam valor;

- Redução de $30 \%$ na movimentação do operador dentro da célula;

- Redução de $15 \%$ nos retrabalhos que ocasionavam parada na célula;

- Redução de 5\% na parada da célula por falta de matériaprima;

- Aumento de 15 pontos percentuais na disponibilidade da célula;

- Redução de $7 \%$ no tempo de ciclo da célula. 


\section{REVISTA}

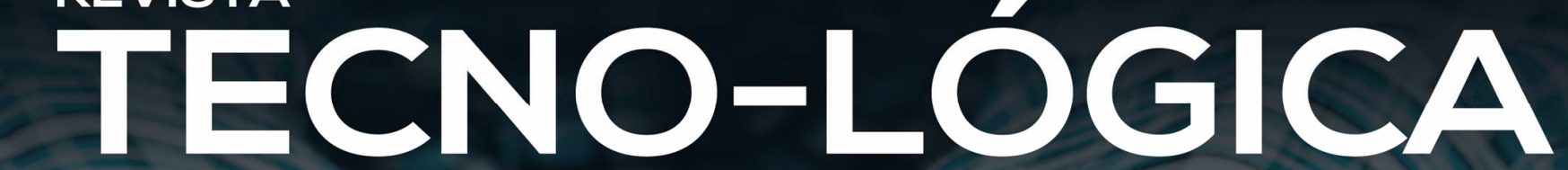

Edição Especial com publicação de trabalhos selecionados do V SIGEPRO

Grande parte dos resultados foram atingidos devido à dedicação da equipe envolvida e a motivação dos operadores em visualizar a possibilidade de serem mais eficientes com qualidade e segurança.

\subsection{Avaliações de Resultados}

A sequência de etapas do método direcionou para uma análise sistemática, que auxilia na identificação e quantificação dos desperdícios, bem como, orienta o planejamento de melhorias para a redução desses desperdícios. Ao final, o método leva ao estabelecimento de um trabalho padrão, em uma situação mais eficiente, considerando o takt time, o tempo de ciclo planejado, o número de operadores e equipamentos, a sequência de atividades, os estoques em processo, o layout, os pontos de atenção em segurança e qualidade. O trabalho de análise das ocorrências pontuais gerou a definição de padrões e a atualização da documentação do posto de trabalho, como citado por Marksberry, Rammohan e Vu [21] e Mor et al. [13] em projetos desta natureza. Desse modo, o processo como um todo se beneficiou por um fluxo mais claro de trabalho, inclusive facilitando o treinamento e a capacitação dos operadores com o trabalho padronizado. Esse achado corrobora os dados de pesquisa em De Freitas e Da Silva [19]. A redução de retrabalho por não-conformidades e a diminuição das paradas na célula de manufatura por falta de matéria-prima são resultados semelhantes aos encontrados em Marksberry, Rammohan e Vu [21] com o trabalho padronizado. A melhora no índice de disponibilidade da célula de manufatura converge para a sugestão de Dias et al. [18] sobre a possibilidade de o trabalho padronizado impactar no OEE (Overall Equipment Effectiveness). Em consonância com De Freitas e Da Silva [19], os resultados do estudo reforçam a importância do envolvimento de todos ao longo do projeto de implementação, principalmente dos operadores. O papel da liderança foi fundamental na condução das ações, incluindo a etapa de desenvolvimento interno de competências [11]. As dificuldades na trajetória foram tratadas como estímulos de busca por informações na literatura sobre o trabalho padronizado, por troca de experiência entre os líderes, técnicos e operadores. O engajamento da equipe permitiu ampla multiplicação de conhecimento e eficácia no detalhamento das ações [1]. Ademais, as mudanças não exigiram investimento financeiro em máquinas, repetindo o caso de Mor et al. [13] com o trabalho padronizado. O fato contribuiu para o retorno da iniciativa com o negócio e valorizou os esforços da equipe do ponto de vista gerencial. Por fim, os achados desta pesquisa podem ser considerados como extensivos para outras células da empresa, com o mesmo conceito de fluxo de atividades.

\section{Conclusões}

Este trabalho foi desenvolvido a partir da necessidade real de uma empresa de melhorar seu desempenho produtivo. Para tanto, decidiu-se implementar o trabalho padronizado, buscando estabilidade e transparência no processamento de uma célula de manufatura. As mudanças com o projeto alcançaram redução de $53 \%$ nas atividades que não agregam valor, redução de $30 \%$ na movimentação do operador dentro da célula, redução de $15 \%$ em retrabalhos, redução de $5 \%$ em paradas da célula por falta de matéria-prima, redução de $7 \%$ no tempo de ciclo da célula e aumento de 15 pontos percentuais na disponibilidade da célula pesquisada. Porém, é necessário esclarecer que o estudo desenvolvido durante esta pesquisa foi o primeiro ciclo para a padronização do trabalho na empresa. Ou seja, o trabalho padronizado não é uma aplicação pontual, e sim cíclica. Para sustentar o nível obtido, o trabalho padronizado deve ser revisado regularmente [20]. De forma ampla, a implementação do trabalho 


\section{REVISTA}
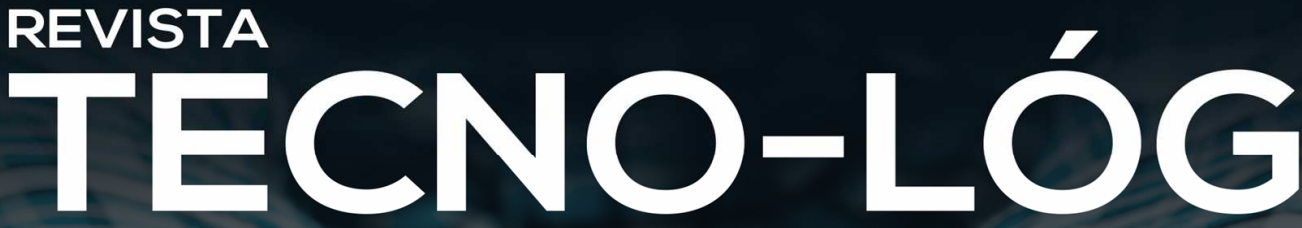

ISSN 1982-6753

Edição Especial com publicação de trabalhos selecionados do V SIGEPRO

padronizado na empresa objeto de estudo permitiu efetivo controle do conteúdo das atividades, das sequências e dos tempos prédeterminados para a realização das tarefas, as atividades geradoras de desperdício foram identificadas e minimizadas, o fluxo do processo tornou-se visível, o treinamento da operação foi simplificado e a gestão visual no posto de trabalho foi adotada.

Apesar dos benefícios alcançados para a empresa e a aprendizagem gerada com a pesquisa, os resultados merecem ser observados no contexto da aplicação. Portanto, o trabalho padronizado é considerado um elemento necessário, mas não um fator suficiente para assegurar a qualidade, a segurança e o treinamento operacional em um ambiente produtivo [20]. Nesse sentido, futuras pesquisas podem tratar das implicações do trabalho padronizado com apoio de análises estatísticas mais profundas [14], assim como investigar sua influência sobre a capacidade produtiva a longo prazo [18] ou aspectos de saúde e segurança ocupacional [19]. Além disso, pode estudar o uso complementar ao trabalho padronizado de tecnologias digitais [20], como a realidade aumentada, a simulação computacional ou outras tecnologias habilitadoras da Indústria 4.0.

\section{PRODUCTIVE PERFORMANCE ADVANCE BY IMPLEMENTING STANDARDIZED WORK IN A MANUFACTURING CELL}

\begin{abstract}
This article details and evaluates the implementation of standardized work in a manufacturing cell. The study aims at increasing the productive performance of a Brazilian company in the agricultural implements sector. In order to meet this internal demand for improvement, an action research was conducted to develop an action plan based on lean thinking,
\end{abstract}

explore the original data of the studied environment, propose solutions and analyze the impacts with the application of standardized work in the investigated context. The results achieved were a reduction of $53 \%$ in non-value adding activities, reduction of $30 \%$ in operator movement within the cell, reduction of $15 \%$ in rework, reduction of $5 \%$ in cell stoppages due to lack of raw material, reduction of $7 \%$ in the cell cycle time and an increase of 15 percentage points in the availability of the surveyed cell. In general, the implementation of standardized work in the company under study allowed effective control of the content of activities, sequences and predetermined times for the performance of tasks. In addition, waste-generating activities were identified and minimized, the process flow became visible, operation training was simplified and visual management at the workplace was adopted.

Keywords: Lean production. Standardized work. Action research.

\section{Referências}

[1] CAMARGO, A. DE O.; DA SILVA, M. G.; SIMÕES, W. L. Contribuições de um evento kaizen para a produção de painéis eletrônicos automotivos: um estudo de caso. Brazilian Journal of Production Engineering, Vol. 4, n. 4, p. 24-43, 2018.

[2] GLOVER, W. J. et al. Characteristics of established kaizen event programs: An empirical study. International Journal of Operations and Production Management, Vol. 33, n. 9, p. 1166-1201, 2013.

[3] DA CAS, F. et al. Implicações da redução de setup na produtividade da indústria farmacêutica. Revista GEINTEC, Vol. 5, n. 1, p. 1764-1779, mar. 2015.

[4] FERREIRA, R. S.; DA SILVA, M. G. Lean office: uma aplicação no planejamento de ordens de manutenção. Revista de Iniciação Científica da ULBRA, n. 16, p. 187-203, 2018.

[5] CHUGANI, N. et al. Investigating the green impact of Lean, Six Sigma and Lean Six Sigma. International Journal of Lean Six Sigma, Vol. 8, n. 1, p. 7-32, 2017.

A matéria publicada nesse periódico é licenciada sob forma de uma Licença Creative Commons - Atribuição 4.0 Internacional http://creativecommons.org/licenses/by/4.0/ 


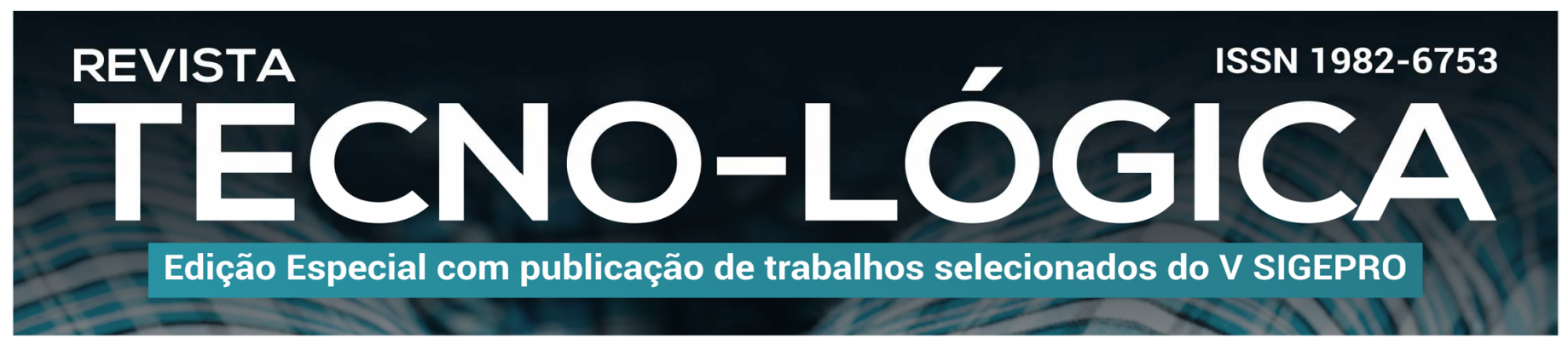

[6] BAUMER-CARDOSO, M. I. et al. Simulation-based analysis of catalyzers and trade-offs in Lean \& Green manufacturing. Journal of Cleaner Production, Vol. 242, p. 118411, 2020.

[7] SHAH, R.; WARD, P. T. Defining and developing measures of lean production. Journal of Operations Management, Vol. 25, n. 4, p. 785-805, 2007.

[8] MACPHERSON, W. G. et al. Kaizen: a Japanese philosophy and system for business excellence. Journal of Business Strategy, Vol. 36, n. 5, p. 3-9, 2015.

[9] LEME, R. D. et al. Creating value with less impact: Lean, green and ecoefficiency in a metalworking industry towards a cleaner production. Journal of Cleaner Production, Vol. 196, p. 517-534, 2018.

[10] AGUILAR-ESCOBAR, V. G.; BOURQUE, S.; GODINO-GALLEGO, N. Hospital kanban system implementation: Evaluating satisfaction of nursing personnel. Investigaciones Europeas de Direccion y Economia de la Empresa, Vol. 21, n. 3, p. 101-110, 2015.

[11] DA SILVA, M. G. Jidoka: Conceitos e aplicação da autonomação em uma empresa da indústria eletrônica. Espacios, Vol. 37, n. 2, p. 17, 2016.

[12] MATZKA, J.; DI MASCOLO, M.; FURMANS, K. Buffer sizing of a Heijunka Kanban system. Journal of Intelligent Manufacturing, Vol. 23, p. 49-60, 2012 .

[13] MOR, R. S. et al. Productivity gains through standardization-of-work in a manufacturing company. Journal of Manufacturing Technology Management, Vol. 30, n. 6, p. 899-919, 2019.

[14] MA, J. et al. The relationships between shop floor management and QCCs to support Kaizen. International Journal of Quality and Reliability Management, Vol. 35 , n. 9 , p. 1941-1955, 2018.

[15] PACHECO, D. A. DE J. et al. Exploring the integration between Lean and the Theory of Constraints in Operations Management. International Journal of Lean Six Sigma, Vol. 10, n. 3, p. 718-742, 2019.

[16] KURILOVA-PALISAITIENE, J.; SUNDIN, E.; POKSINSKA, B. Remanufacturing challenges and possible lean improvements. Journal of Cleaner Production, Vol. 172, p. 3225-3236, 2018.

[17] CORREIA, D. et al. Improving manual assembly lines devoted to complex electronic devices by applying Lean tools. Procedia Manufacturing 17 - 28th International Conference on Flexible Automation and Intelligent Manufacturing. Anais...2018.
[18] DIAS, P. et al. Analysis and improvement of an assembly line in the automotive industry. Procedia Manufacturing 38 - 29th International Conference on Flexible Automation and Intelligent Manufacturing. Anais...2019.

[19] DE FREITAS, E. S.; DA SILVA, M. G. Pesquisa-ação sobre a implementação do trabalho padronizado em uma célula de manufatura de uma fábrica de tratores. Espacios, Vol. 38, n. 46, p. 21, 2017.

[20] KURDVE, M. Digital assembly instruction system design with green lean perspective-Case study from building module industry. Procedia CIRP $72-51$ st CIRP Conference on Manufacturing Systems. Anais...2018.

[21] MARKSBERRY, P.; RAMMOHAN, R.; VU, D. A systems study on standardised work: A Toyota perspective. International Journal of Productivity and Quality Management, Vol. 7, n. 3, p. 287-303, 2011.

[22] MELLO, C. H. P. et al. Pesquisa-ação na engenharia de produção: proposta de estruturação para sua condução. Production, Vol. 22, n. 1, p. 1-13, 2012.

[23] MAHAJAN, M. et al. Implementation of lean techniques for sustainable workflow process in Indian motor manufacturing unit. Procedia Manufacturing 35 - 2nd International Conference on Sustainable Materials Processing and Manufacturing. Anais...2019.

[24] SABADKA, D. et al. Optimization of Production Processes Using the Yamazumi Method. Advances in Science and Technology Research Journal, Vol. 11, n. 4, p. 175-182, 2017. 